\title{
Isoluminance and contingent color aftereffects
}

\author{
LORRAINE G. ALLAN, SHEPARD SIEGEL, CHANDANI KULATUNGA-MORUZI, \\ THOMAS EISSENBERG, and C. ANDREW CHAPMAN \\ McMaster University, Hamilton, Ontario, Canada
}

\begin{abstract}
In the typical induction of the orientation-contingent color aftereffect (CCAE), the stimuli are composed of elements that differ in both color and luminance. Three experiments are reported that show that chromatic contrast between stimulus elements is insufficient for the induction of the orientationCCAE and that luminance contrast is necessary. These experiments expand on previous research concerned with the role of luminance contrast in the induction of orientation-CCAEs by eliminating alternative explanations.
\end{abstract}

The orientation-contingent color aftereffect (CCAE) typically is induced by alternating two complementarily colored and orthogonally oriented grids every few seconds for several minutes (McCollough, 1965). For example, a grid constructed of black-and-green horizontal bars might be alternated with a grid constructed of blackand-red vertical bars. Following such induction, complementary color aftereffects contingent on grid orientation are noted-black-and-white assessment grids appear colored. In this example, the white space between the black horizontal bars appears pink and the white space between the black vertical bars appears green.

The grids used in the induction of the orientationCCAE are usually composed of chromatic and achromatic (black) bars that differ in luminance. A few studies have examined the role of the luminance contrast ${ }^{1}$ between the chromatic and achromatic bars in the induction of the orientation-CCAE. Ellis (1977) and Mikaelian (1980) systematically varied luminance contrast by increasing the luminance of the achromatic bars from black to various shades of gray. They reported that the size of the orientation-CCAE decreased with decreasing luminance contrast and concluded that isoluminant grids were ineffective in inducing an orientation-CCAE. Allan, Siegel, Toppan, and Lockhead (1991) also reported that induction with grids composed of gray and colored isoluminant bars did not result in an orientation-CCAE. These studies are in agreement with Stromeyer's (1978) often-cited conclusion, based on unpublished data, that luminance contrast is necessary for the induction of the orientation-CCAE.

This research was supported by grants to L.G.A. and S.S. from the Natural Sciences and Engineering Research Council of Canada and the U.S. National Institutes of Mental Health. The data in Experiments 1 and 2 are reported in a McMaster Honors B. Arts \& Sc. thesis submitted by C.K.-M. T.E. is now at Virginia Commonwealth University, and C.A.C. is now at the Université de Montreal. We thank R. P. O'Shea, R. L. Savoy, and two anonymous referees for helpful comments on an earlier draft of this manuscript. Correspondence should be addressed to L. G. Allan or S. Siegel, Department of Psychology, McMaster University, Hamilton, ON, Canada L8S 4K1 (e-mail: allan@mcmaster.ca or siegel@mcmaster.ca).
Although the existing data suggest that luminance contrast is necessary for the induction of the orientation$\mathrm{CCAE}$, an examination of the published experiments reveals that the absence of the orientation-CCAE after isoluminant induction might be attributable to variables other than the luminance contrast of the induction grids. The three experiments reported in the present paper explore this possibility.

\section{GENERAL METHOD}

\section{Subjects}

A total of 59 subjects participated in the three experiments. The subjects had no previous experience in contingent aftereffect tasks, and each subject participated in only one of the three experiments. All but 2 of the subjects were students enrolled in introductory psychology at McMaster University who received course credit for their participation. The remaining 2 subjects (Experiment 2) were 5 th year engineering students who volunteered.

\section{Apparatus}

A Tandy 3000 computer, equipped with a VGA display card, was used in Experiments 1 and 2. The stimuli were displayed in the center of a Zenith "flat screen" monitor (Model 1490). Illuminance (lux) and chromaticity (CIE $x$-and $y$-coordinates) values for the stimuli in Experiments 1 and 2 have been reported in Allan et al. (1991) and are reproduced in Table 1. When feedback about response accuracy was given to the subject, it was provided by a message ("correct" or "error") printed on the monitor.

A Macintosh computer, equipped with an 8-bit video display card, was used in Experiment 3. Stimuli were displayed in the center of an Apple color monitor (Model M0401PA). Luminance $\left(\mathrm{cd} / \mathrm{m}^{2}\right)$ and chromaticity (CIE $x$ - and $y$-coordinates) values for the stimuli in Experiment 3 are shown in Table 2. A computer-generated voice provided auditory feedback regarding response accuracy.

\section{Procedure}

An experimental session consisted of four phases: practice, preinduction assessment, induction, and postinduction assessment. The experimenter was present in the room throughout the session, but did not observe the stimulus display. The room lights were off during the four phases, but were turned on for $2 \mathrm{~min}$ between induction and postinduction assessment to minimize the influence of simple afterimages on postinduction assessment. A variant of the method of constant stimuli (Allan et al., 1991) was used in practice and in the two assessment phases. Background music was played during induction. 
Table 1

Illuminance (Lux) and Chromaticity Values

(CIE $x$-and $y$-Coordinates) for the Tandy 3000 in Experiments 1 and 2

\begin{tabular}{lccc}
\hline & Illuminance & $x$ & $y$ \\
\hline $\begin{array}{l}\text { Achromatic bars } \\
\text { Gray }\end{array}$ & 12.7 & .30 & .34 \\
$\begin{array}{l}\text { Induction colors } \\
\text { Red }\end{array}$ & 13.1 & .55 & .31 \\
Green & 48.9 & .31 & .60 \\
$\quad$ Green & 12.7 & .31 & .60 \\
Assessment colors & & & \\
P2 & 57.0 & .30 & .31 \\
P1 & 59.3 & .30 & .32 \\
0 & 62.0 & .30 & .33 \\
G1 & 62.6 & .30 & .34 \\
G2 & 63.0 & .30 & .35 \\
\hline
\end{tabular}

Instructions were provided to the subjects before each phase. Before the practice phase and each assessment phase, subjects were told (or reminded) that they were participating in a color discrimination task in which they would be asked to determine whether the stimuli displayed on the monitor screen were pink or green. They were instructed to be as accurate as possible, but to guess if they were unsure of the color. Before the induction phase, subjects were told that they should observe the screen. Subjects were not given any instructions regarding eye fixation, but were told (or reminded) before each phase to maintain their heads in an upright position.

\section{EXPERIMENT 1}

In the experiments reported by Allan et al. (1991), Ellis (1977), and Mikaelian (1980), the role of luminance contrast in the induction of the orientation-CCAE was examined by using low-contrast grids during both induction and assessment. In Allan et al., the gray bars of the isoluminant induction grids were also used in assessment. In Mikaelian, the luminance contrast ratio of the assessment grids was 0.6 , and in Ellis, the space-averaged luminance of the assessment grids was the same as that in the induction grids. ${ }^{2}$ On the basis of his review of the available data, Stromeyer (1978) concluded that the CCAE was smaller on low-contrast assessment grids than on high-contrast assessment grids. Thus, it is possible that the reported ineffectiveness of isoluminant grids to elicit an orientation-CCAE resulted from the use of lowcontrast assessment stimuli, rather than isoluminant induction stimuli. In Experiment 1, in order to test this hypothesis, subjects were induced with either high- or low-contrast (isoluminant) grids and were also assessed with either high- or low-contrast grids.

\section{Method}

Stimuli. The induction and assessment stimuli were the same as those used by Allan et al. (1991). The stimuli were horizontal and vertical grids, $9.0 \mathrm{~cm}$ wide $\times 9.4 \mathrm{~cm}$ high, subtending approximately $4.1^{\circ}$ and $4.3^{\circ}$ of visual angle, respectively. Each grid was composed of 24 equal-width bars, 12 achromatic bars alternating with 12 chromatic bars. A horizontal bar subtended $.18^{\circ}$ of visual angle and a vertical bar subtended $.17^{\circ}$ of visual angle. The achromatic bars of the high-contrast grids were black, and the achromatic bars of the low-contrast grids were gray. The monitor screen around the grid was black.
Induction. Complementarily colored orthogonal grids, greenhorizontal and red-vertical, were alternated every $3 \mathrm{sec}$ during induction. The green and red were effectively isoluminant using Savoy's (1987) criteria (see Table 1). There were 500 stimulus presentations, 250 presentations of each induction stimulus. The induction phase lasted approximately $25 \mathrm{~min}$.

Assessment. During both pre- and postinduction assessments, there were 50 presentations of the horizontal grid and 50 presentations of the vertical grid. The chromatic bars of the assessment grids could be one of five colors: one of two shades of pale pink ( $\mathrm{P} 2$ and $\mathrm{P} 1$, with $\mathrm{P} 2$ being more saturated than $\mathrm{P} 1)$, one of two shades of pale green ( $G 2$ and $G 1$, with $G 2$ being more saturated than $G 1$ ), or achromatic $(0)$. Orientation (horizontal or vertical) and color $(\mathrm{P} 2$, $\mathrm{P} 1,0, \mathrm{G} 1, \mathrm{G} 2$ ) were randomly ordered, with the restriction that each orientation was presented in each color 10 times. On each assessment trial, the subject indicated whether the grid appeared "green" or "pink." The assessment grid remained on the screen until the experimenter entered the subject's response on the computer keyboard. The screen was then black for $1 \mathrm{sec}$ before the next assessment stimulus was presented.

Subjects were familiarized with the assessment procedure prior to the start of the experiment. Before preinduction assessment, subjects received 16 practice trials, with feedback regarding response accuracy. For each practice trial, the grid (horizontal or vertical) was one of the four unsaturated colors $(\mathrm{G} 1, \mathrm{G} 2, \mathrm{P1}$, or P2). Each of the eight color-pattern combinations was presented twice in random order.

Design. There were four groups, formed by combining two induction grids (high-contrast induction $\left[\mathrm{HC}_{\mathrm{l}}\right]$ and low-contrast induction $\left[\mathrm{LC}_{\mathrm{I}}\right]$ ) with two assessment grids (high-contrast assessment $\left[\mathrm{HC}_{\mathrm{A}}\right]$ and low-contrast assessment $\left.\left[\mathrm{LC}_{\mathrm{A}}\right]\right)$. The luminance contrast ratio was 1.0 for the $\mathrm{HC}$ induction grids and 0 for the low-contrast induction grids; the luminance contrast ratio was 1.0 for the highcontrast assessment grids and ranged from .64 to .66 for the five low-contrast assessment grids. Seven subjects were assigned to each group. Subjects in the $\mathrm{HC}_{\mathrm{I}} / \mathrm{HC}_{\mathrm{A}}$ group were induced and assessed as in a typical orientation-CCAE experiment; the achromatic bars were black during both induction and assessment. Subjects in the $\mathrm{LC}_{1} / \mathrm{LC}_{\mathrm{A}}$ group were induced and assessed as in the isoluminant group in Allan et al. (1991); the induction grids were isoluminant and the achromatic bars in assessment were gray. Subjects in the $\mathrm{HC}_{\mathrm{I}} / \mathrm{LC}_{\mathrm{A}}$ group were induced with grids with black bars and assessed with grids with gray bars. Subjects in the $\mathrm{LC}_{\mathrm{I}} / \mathrm{HC}_{\mathrm{A}}$ group were induced with grids with gray bars and assessed with grids with black bars.

\section{Results}

The mean number of green responses $(\# \mathrm{G})$ to each assessment orientation, across the five assessment colors, was determined for each subject in pre- and postinduction assessment. The range of values for $\# \mathrm{G}$ was 0 to 10 :

Table 2

Luminance $\left(\mathrm{cd} / \mathrm{m}^{2}\right)$ and Chromaticity Values (CIE $x$ - and $y$-Coordinates) for the Macintosh in Experiment 3

\begin{tabular}{lccc}
\hline & Luminance & $x$ & $y$ \\
\hline $\begin{array}{l}\text { Achromatic bars } \\
\text { Gray }\end{array}$ & 16 & .26 & .32 \\
$\begin{array}{l}\text { Induction colors } \\
\text { Magenta }\end{array}$ & 16 & .26 & .13 \\
$\quad$ Green & 16 & .27 & .60 \\
Assessment colors & & & \\
P2 & 60 & .28 & .30 \\
P1 & 61 & .28 & .30 \\
0 & 63 & .27 & .30 \\
G1 & 61 & .27 & .31 \\
G2 & 60 & .27 & .31 \\
\hline
\end{tabular}



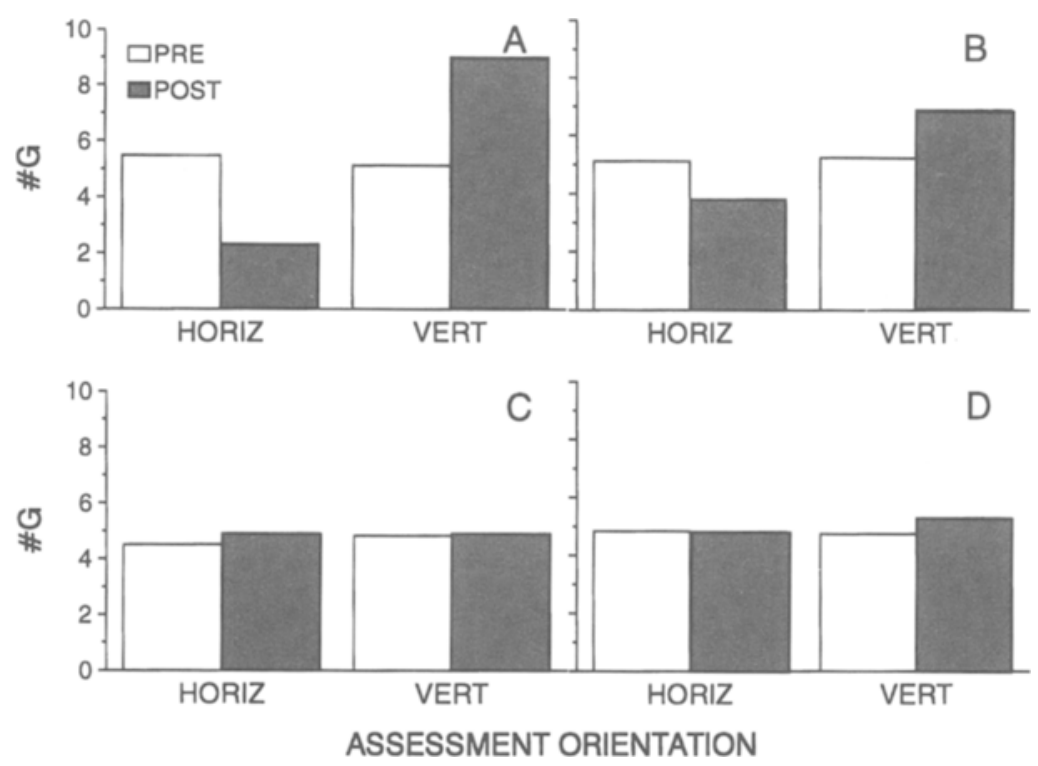

Figure 1. Mean pre- and postinduction \#G as a function of assessment orientation, horizontal (Horiz) and vertical (Vert), for groups $\mathrm{HC}_{\mathrm{I}} / \mathrm{HC} \mathrm{C}_{\mathrm{A}}(\mathrm{A}), \mathrm{HC}_{\mathrm{I}} / \mathrm{LC}_{\mathrm{A}}(\mathrm{B}), \mathrm{LC}_{\mathrm{I}} / \mathrm{HC}_{\mathrm{A}}$ $(C)$, and $L C_{\mathrm{P}} / \mathrm{LC}_{\mathrm{A}}(\mathrm{D})$ in Experiment 1.

a value of 0 indicates that a grid orientation was never judged as green, and a value of 10 that it was always judged as green.

Figure I displays \#G as a function of assessment orientation (horizontal and vertical) for the four groups. For the two groups induced with grids with black bars $\left[\mathrm{HC}_{\mathrm{I}} / \mathrm{HC}_{\mathrm{A}}\right.$ (Figure $1 \mathrm{~A}$ ) and $\mathrm{HC}_{\mathrm{I}} / \mathrm{LC}_{\mathrm{A}}$ (Figure 1B)], the horizontal grid (induced in green) appeared less green ( $\# \mathrm{G}$ decreased from pre- to postinduction) and the vertical grid (induced in red) appeared more green ( $\# \mathrm{G}$ increased from pre- to postinduction), indicating the induction of an orientation-CCAE. For the two groups induced with isoluminant grids $\left(\mathrm{LC}_{\mathrm{I}} / \mathrm{HC}_{\mathrm{A}}\right.$, Figure $1 \mathrm{C}$; and $\mathrm{LC}_{\mathrm{l}} / \mathrm{LC}_{\mathrm{A}}$, Figure 1D), there was little change in $\# \mathrm{G}$ from pre- to postinduction, suggesting that an orientationCCAE was not induced. A 4 (group: $\mathrm{HC}_{\mathrm{I}} / \mathrm{HC}_{\mathrm{A}}, \mathrm{HC}_{\mathrm{I}} / \mathrm{LC}_{\mathrm{A}}$, $\mathrm{LC}_{\mathrm{I}} / \mathrm{HC}_{\mathrm{A}}$, or $\left.\mathrm{LC}_{1} / \mathrm{LC}_{\mathrm{A}}\right) \times 2$ (assessment phase: pre- or postinduction) $\times 2$ (assessment orientation: horizontal or vertical) mixed-design analysis of variance (ANOVA) was performed on \#G to evaluate statistically the presence of orientation-CCAEs after high-contrast induction and the absence of orientation-CCAEs after isoluminant induction. The three-way interaction between group, assessment phase, and assessment orientation was significant $[F(3,24)=39.10, p<.001]$. Planned comparisons ${ }^{3}$ revealed that the interaction between assessment phase and assessment orientation was significant for the two $\mathrm{HC}$ induction groups $[F(1,24)=179.13, p<.001$ for $\mathrm{HC}_{1} / \mathrm{HC}_{\mathrm{A}}$, and $F(1,24)=32.02, p<.001$ for $\left.\mathrm{HC}_{\mathrm{l}} / \mathrm{LC}_{\mathrm{A}}\right]$, confirming that an orientation-CCAE was induced. Planned comparisons also revealed that the interaction between assessment phase and assessment orientation was not significant for the two LC induction groups ( $p \mathrm{~s}>$
.05 for both $\mathrm{LC}_{\mathrm{I}} / \mathrm{HC}_{\mathrm{A}}$ and $\left.\mathrm{LC}_{\mathrm{I}} / \mathrm{LC}_{\mathrm{A}}\right)$, confirming the absence of an orientation-CCAE.

Figure 1 suggests that the orientation-CCAE was larger in Group $\mathrm{HC}_{\mathrm{I}} / \mathrm{HC}_{\mathrm{A}}$ than in Group $\mathrm{HC}_{1} / \mathrm{LC}_{\mathrm{A}}$. The size of the orientation-CCAE can be summarized by one number, the "CCAE score," which is the algebraic sum of the change in \#G from pre- to postinduction for the two orientations (see Siegel, Allan, \& Eissenberg, 1992). A CCAE score was determined for each subject and the mean CCAE score is shown in Figure 2 for each group. A between-subjects ANOVA on the CCAE scores indicated a significant main effect of group $[F(3,24)=39.19$, $p<.001$ ], and Tukey post hoc comparisons confirmed that the orientation-CCAE for the $\mathrm{HC}_{\mathrm{I}} / \mathrm{HC}_{\mathrm{A}}$ group was significantly larger than that for the $\mathrm{HC}_{\mathrm{I}} / \mathrm{LC}_{\mathrm{A}}$ group $(p<.001)$.

\section{Discussion}

Experiment 1 employed a $2 \times 2$ factorial design to assess the effects of high- and low-luminance contrast in induction and assessment. The data indicate that induction with high-contrast grids resulted in significant orientation-CCAEs whether assessed with high- or lowcontrast grids. High-contrast induction did elicit a significantly smaller CCAE when assessed with the lowcontrast grid (Group $\mathrm{HC}_{\mathrm{I}} / \mathrm{LC}_{\mathrm{A}}$ ) compared with the high-contrast grid (Group $\mathrm{HC}_{1} / \mathrm{HC}_{\mathrm{A}}$ ). This outcome is consistent with other findings indicating a decrease in the size of the CCAE as the assessment stimulus decreases in similarity to the induction stimulus (see Allan \& Siegel, 1986) ${ }^{4}$

Induction with isoluminant grids did not result in an orientation-CCAE on either high- or low-contrast as- 


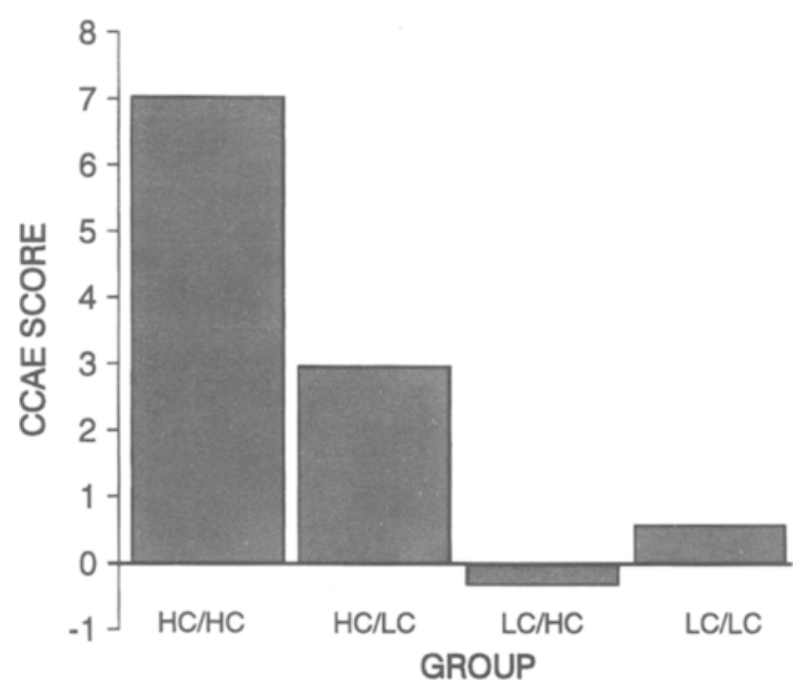

Figure 2. Mean contingent color aftereffect (CCAE) score for each group in Experiment 1.

sessment grids. Thus, the absence of an orientationCCAE after isoluminance induction does not appear to be due to the use of low-contrast assessment grids.

\section{EXPERIMENT 2}

Experiment 2 used a congruent/incongruent design to further explore the possibility that the failure to observe the orientation-CCAE with isoluminant grids was a failure in the assessment of the CCAE. An orientation-CCAE can be enhanced by additional induction with congruent orientation-color pairing or attenuated by additional induction with incongruent orientation-color pairing (see Allan \& Siegel, 1986). After induction with greenhorizontal and red-vertical, for example, the size of the CCAE can be increased by additional congruent induction (i.e., green-horizontal and red-vertical) or decreased by additional incongruent induction (i.e., green-vertical and red-horizontal). Experiment 2 examined whether the orientation-CCAE induced with high-contrast grids would be enhanced by congruent isoluminant induction and attenuated by incongruent isoluminant induction.

\section{Method}

Induction was similar to that in Experiment 1 except that there were two induction phases. During Induction 1, a high-contrast greenhorizontal grid alternated with a high-contrast red-vertical grid. Induction 1 lasted approximately 10 min, with 200 presentations, 100 of each grid. During Induction 2, the grids were isoluminant. For the congruent group $(n=8)$, orientation-color pairing was the same as in Induction 1 (i.e., green-horizontal and red-vertical). For the incongruent group ( $n=8)$, orientation-color pairing was incongruent with that used in Induction 1 (i.e., green-vertical and redhorizontal ). Induction 2 lasted approximately $15 \mathrm{~min}$, with 300 presentations, 150 of each grid. Assessment for both groups was identical to that for the high-contrast assessment groups in Experiment 1 that is, the achromatic bars were black.

\section{Results and Discussion}

Figure 3 displays \#G as a function of assessment orientation (horizontal and vertical) for the two groups. For both groups, the horizontal grid appeared less green ( $\# \mathrm{G}$ decreased from pre- to postinduction) and the vertical grid appeared more green (\#G increased from pre- to postinduction), indicating the induction of an orientation-

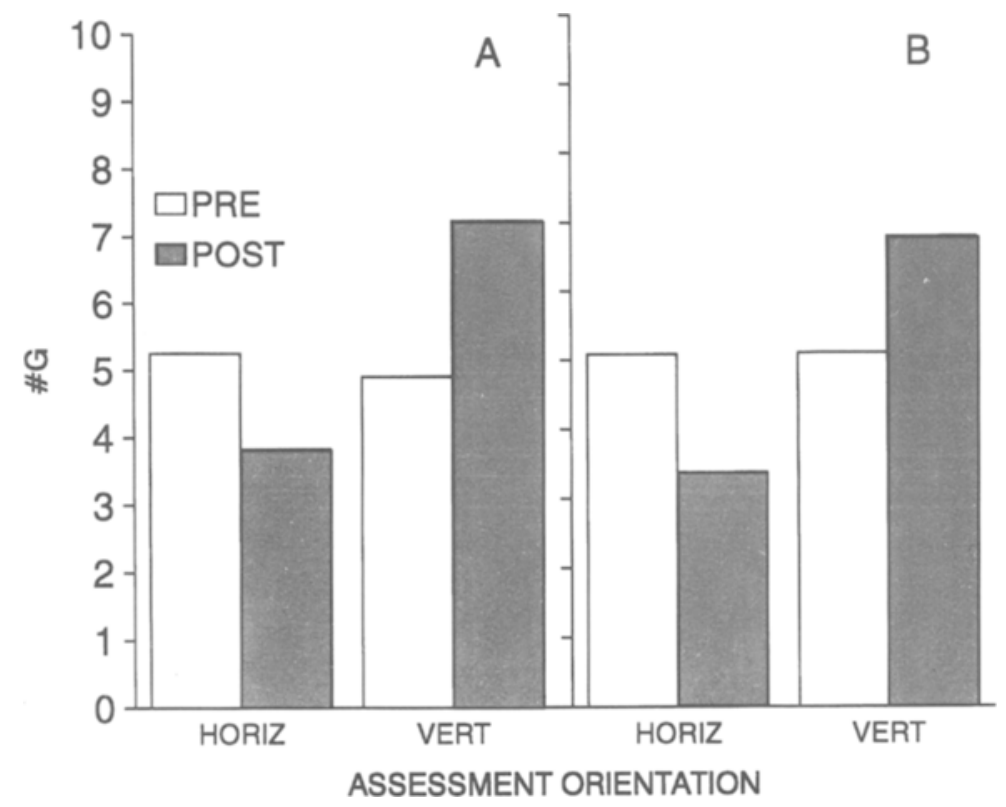

Figure 3. Mean pre- and postinduction \#G as a function of assessment orientation (horizontal and vertical) for the congruent (A) and incongruent (B) groups in Experiment 2. 
CCAE. The data in Figure 3 suggest that the size of the orientation-CCAE did not differ between the two groups. A 2 (group: congruent or incongruent) $\times 2$ (assessment phase: pre- or postinduction) $\times 2$ (assessment orientation: horizontal or vertical) mixed-design ANOVA, performed on $\# \mathrm{G}$, indicated that the interaction between assessment phase and assessment orientation was significant $[F(1,14)=122.24, p<.001]$, confirming that an orientation-CCAE was induced in both groups. The group main effect was not significant, and it did not interact significantly with the other factors (all $p \mathrm{~s}>.05$ ), confirming the absence of a group difference.

The data from Experiment 2 show that isoluminant induction was ineffective. If isoluminant induction had been effective during Induction 2 , it would have enhanced the CCAE in the congruent group and attenuated the CCAE in the incongruent group; that is, the size of the CCAE would have been larger in the congruent group than in the incongruent group. At the end of Induction 2, the size of the orientation-CCAE was not different in the two groups.

\section{EXPERIMENT 3}

Experiments 1 and 2 add to the evidence that orientation-CCAEs are not observed or altered after induction with isoluminant grids. The results of these experiments suggest that the absence of a CCAE after isoluminant induction cannot be attributed to the assessment (rather than induction) of the CCAE.

Experiment 3 investigated the possibility that the ineffectiveness of isoluminant grids to induce an orientationCCAE is due to their relatively low salience. Eissenberg, Allan, Siegel, and Petrov (1995) noted that an induction grid is actually a compound, which, in addition to orientation, has a square form and is surrounded by a black frame (the computer screen around the grid). That is, a horizontal grid stimulus is a compound consisting of at least three elements: bar orientation (horizontal), form (square), and frame lightness (black). Each of these elements is capable of eliciting a CCAE (see Siegel et al., 1992).

It has been shown that more salient elements of a compound "overshadow" (Kamin, 1969) less salient elements during induction, preventing the less salient elements from eliciting CCAEs (e.g., Brand, Holding, \& Jones, 1987; Eissenberg et al., 1995; Siegel \& Allan, 1985). Eissenberg et al., for example, showed that with high-contrast grids, grid orientation was more salient than frame lightness and that grid orientation overshadowed frame lightness. Although frame lightness can elicit a CCAE in the absence of a grid, it was relatively ineffective in the presence of a grid.

The absence of an orientation-CCAE with isoluminant grid stimuli might be related to the relative salience of the grid and frame components of isoluminant induction stimuli. The isoluminant grid stimuli in Experiments 1 and 2 were compounds composed of a high-contrast frame (the black monitor screen) and low-contrast grids.
It is possible that the high-contrast frame overshadowed the orientation of the low-contrast grids. That is, overshadowing of grid orientation by high-contrast frames might account for the absence of the orientation-CCAE after induction with isoluminant grids surrounded by black frames. Overshadowing of orientation by frame during isoluminant $\mathrm{CCAE}$ induction was investigated in Experiment 3 by varying the salience of the frame relative to the grid. The isoluminant chromatic grids in induction were surrounded by either a black frame (as in previous experiments) or by a gray frame that was isoluminant with the grids.

\section{Method}

Stimuli. The induction and assessment stimuli were horizontal and vertical grids, approximately $5.9 \mathrm{~cm}$ square. Each grid was composed of 20 equal-width bars, 10 achromatic bars alternating with 10 chromatic bars. For high-contrast grids, the achromatic bars were black, and for low-contrast grids, the achromatic bars were gray. Luminance $\left(\mathrm{cd} / \mathrm{m}^{2}\right)$ and chromaticity (CIE $x$ - and $y$-coordinates) values are reported in Table 2 .

Induction and assessment. Complementarily colored orthogonal grids, green-horizontal and magenta-vertical, alternated every 2 sec during induction. There were 450 stimulus presentations, 225 presentations of each induction stimulus. The induction phase lasted approximately $15 \mathrm{~min}$.

There were three groups ( $n=5$ per group). Subjects in Group $\mathrm{HC}_{1} / \mathrm{HC}_{\mathrm{A}}$ were induced and assessed with grids with black bars. For subjects in Group $\mathrm{LC}_{\mathrm{I}} / \mathrm{LC}_{\mathrm{A}}$, the induction grids were isoluminant and the achromatic bars in assessment were gray (luminance contrast ratio was .59). For both groups, the frame surrounding the grid was black. The third group, $\mathrm{LC}_{\mathrm{I}} / \mathrm{LC}_{\mathrm{A}}$ [Gray], differed from Group $\mathrm{LC}_{1} / \mathrm{LC}_{\mathrm{A}}$ in that the frame surrounding the grid was gray. In all other respects, induction and assessment were as in Experiment 1

\section{Results and Discussion}

If isoluminant grids are ineffective in eliciting CCAEs because such grids typically are overshadowed by the more salient frame-lightness cue, then Group $\mathrm{LC}_{\mathrm{I}} / \mathrm{LC}_{\mathrm{A}}$ [Gray] should demonstrate a CCAE despite the use of isoluminant grids in induction. Figure 4 displays $\# \mathrm{G}$ as a function of assessment orientation (horizontal and vertical) for the three groups and shows that an orientationCCAE was induced only in the $\mathrm{HC}_{\mathrm{l}} / \mathrm{HC}_{\mathrm{A}}$ group. This is confirmed by a 3 (group: $\mathrm{HC}_{\mathrm{I}} / \mathrm{HC}_{\mathrm{A}}, \mathrm{LC}_{\mathrm{I}} / \mathrm{LC}_{\mathrm{A}}$, or $\mathrm{LC}_{\mathrm{l}} / \mathrm{LC}_{\mathrm{A}}$ [Gray] $) \times 2$ (assessment phase: pre- or postinduction) $\times 2$ (assessment orientation: horizontal or vertical) mixed-design ANOVA performed on \#G. The three-way interaction between group, assessment phase, and assessment orientation was significant $[F(2,12)=$ $47.77, p<.001]$. Planned comparisons indicated that the interaction between assessment phase and assessment orientation was significant for the $\mathrm{HC}_{\mathrm{l}} / \mathrm{HC}_{\mathrm{A}}$ group $[F(1,12)=141.96, p<.001]$, but not for either of the two isoluminant induction groups $\left(F_{\mathrm{S}}<1.0, p \mathrm{~s}>.05\right)$. An orientation-CCAE was induced in the $\mathrm{HC}_{\mathrm{l}} / \mathrm{HC}_{\mathrm{A}}$ group, but induction with isoluminant grids, whether in a black frame or in a gray frame, did not result in a significant orientation-CCAE. The absence of an orientation-CCAE in the $\mathrm{LC}_{\mathrm{I}} / \mathrm{LC}_{\mathrm{A}}[\mathrm{Gray}]$ group suggests that the ineffec- 


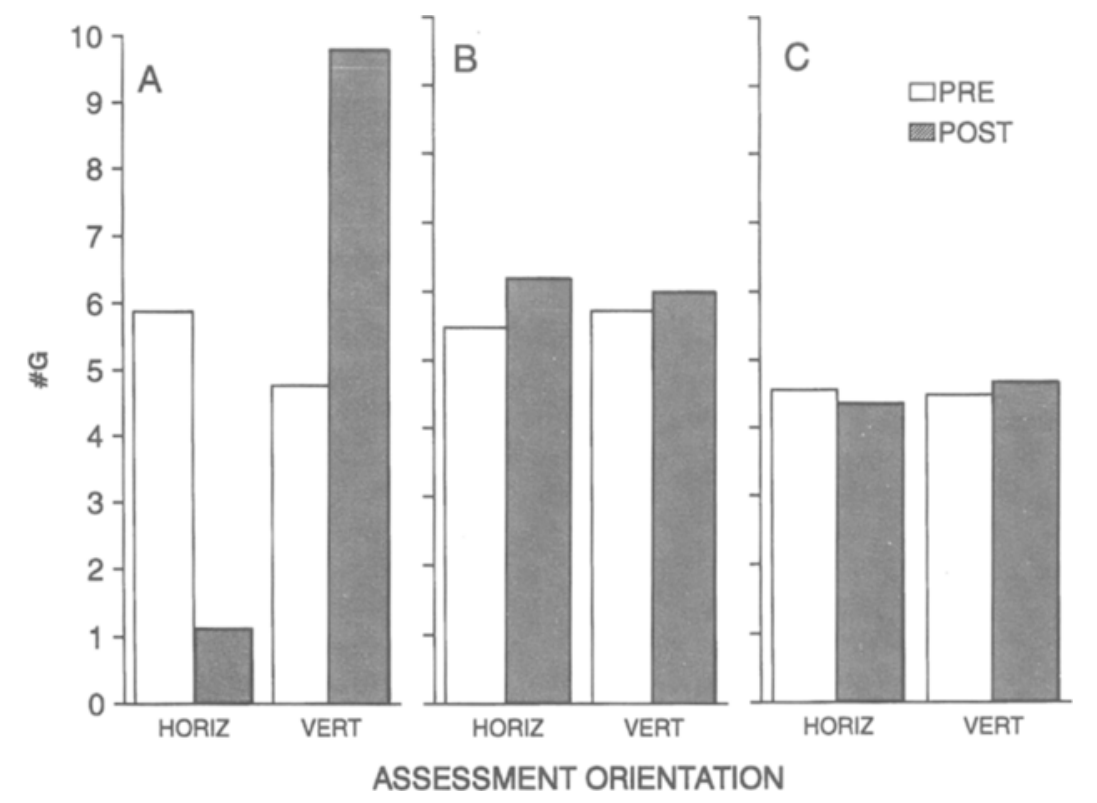

Figure 4. Mean pre- and postinduction \#G as a function of assessment orientation (horizontal and vertical) for groups $\mathrm{HC}_{\mathrm{I}} / \mathrm{HC}_{\mathrm{A}}(\mathrm{A}), \mathrm{LC}_{\mathrm{I}} / \mathrm{LC}_{\mathrm{A}}$ (B), and $\mathrm{LC}_{\mathrm{I}} / \mathrm{LC}_{\mathrm{A}}[\mathrm{Gray}$ (C) in Experiment 3.

tiveness of isoluminant grids in inducing the orientationCCAE is not due to overshadowing of orientation by frame lightness.

\section{GENERAL DISCUSSION}

The data from the three experiments provide clear evidence that luminance contrast is necessary for the induction of the orientation-CCAE. Experiments 1 and 2 investigated the possibility that the absence of an orientation-CCAE after induction with isoluminant grids was due to the assessment of the CCAE rather than to induction. Experiment 1 systematically manipulated luminance contrast in induction and in assessment. Experiment 2 used a congruent/incongruent design. The results of both experiments support the conclusion that induction with isoluminant grids does not result in an orientationCCAE. Experiment 3 provided evidence that the ineffectiveness of isoluminant grids in inducing the orientationCCAE is not due to overshadowing of grid orientation by frame lightness.

The present results show that color contrast without luminance contrast does not result in an orientation-CCAE. Data in the literature, however, indicate that luminance contrast without color contrast does result in a contingent aftereffect. An orientation-contingent achromatic aftereffect has been reported by a number of investigators (Allan \& Tirimacco, 1987; Mikaelian, Linton, \& Phillips, 1990; Over, Broerse, Crassini, \& Lovegrove, 1974). To induce this aftereffect, two orthogonally oriented grids that differ in lightness, rather than in color, are alternated; for example, a horizontal grid consisting of black and light gray bars and a vertical grid consisting of black and dark gray bars. After such induction, the perceived lightness of gray bars is contingent on orientation; in this example, the same gray appears darker as part of a horizontal grid than as part of a vertical grid.

The evidence converges to indicate that luminancedefined edges, but not color-defined edges, are necessary for CCAE induction. Although a number of investigators have stressed the role of edges in CCAE induction, typically no distinction has been made between luminance and color edges. McCollough (1965), for example, attributed CCAEs to color adaptation of orientation-specific edge detectors, but did not specify that these detectors were sensitive only to edges defined by luminance contrast. More recently, Broerse and O'Shea (1995; see also Broerse, Shaw, Dodwell, \& Muir, 1994) have also argued for the importance of edges in the induction of CCAEs and concluded that CCAEs are present only at edges. Broerse and O'Shea did not mention, however, that the edges must be defined by luminance contrast to be effective, and that edges defined only by color contrast are ineffective. Savoy (1987) is one investigator who did address the crucial role of luminance contrast in the induction of CCAEs. He suggested that the processing of edges is dependent on luminance contrast, and that "the notion of 'edgeness' is independent of the existence of a chromatic edge" (p. 16). Savoy noted that the proposition that chromatic contrast does not define an edge is contradicted by our perceptions. When faced with a split field containing an isoluminant red-to-green boundary, a well-defined edge is clearly perceived (see also Kaiser, Herzberg, \& Boyton, 1971). 
The critical role of luminance contrast in the induction of CCAEs has been largely ignored by many of the current theoretical accounts of CCAEs. For example, Bedford (1995) did not address how her perceptual learning account could encompass the failure of isoluminant stimuli to elicit CCAEs. According to this account, CCAEs are induced because real-world objects are constrained to behave in certain ways. If an induction procedure results in a violation of a constraint about a realworld object, an internal malfunction is assumed and subsequently corrected. This internal correction results in a CCAE. During induction of the orientation-CCAE, for example, the two orthogonal grids can be interpreted as the same object tilted $90^{\circ}$ (or the same object viewed with the head tilted $90^{\circ}$ ). During such induction, the constraint - that an object does not change color when the object or head is tilted-is violated. Induction with isoluminant grids, like induction with high-contrast grids, violates the constraint that an object does not change color when the object or head is tilted. Induction with isoluminant grids should, therefore, result in an orientation-CCAE.

Accounts that attribute CCAEs to error-correcting or recalibratory processes (e.g., Barlow, 1990; Barlow \& Foldiak, 1989; Dodwell, 1992; Dodwell \& Humphrey, 1990, 1993; Wolfe \& O'Connell, 1986) have also been silent with regard to isoluminant induction stimuli. According to Dodwell and Humphrey (1990, 1993; Dodwell, 1992), for example, CCAEs are generated because the zero correlation that normally exists between color and pattern is violated by the high correlation imposed during induction. To maintain an internal representation of the zero correlation in the presence of the artificially high correlation during CCAE induction, the system recalibrates to decorrelate color and pattern. Induction with isoluminant grids, like induction with high-contrast grids, violates the zero correlation that normally exists between color and orientation. Induction with isoluminant grids should, therefore, result in a CCAE.

Advocates of the associative account of CCAEs have incorporated an explanation of the failure of isoluminant stimuli to induce CCAEs (e.g., Allan \& Siegel, 1986; Siegel \& Allan, 1985, 1992; Westbrook \& Harrison, 1984). According to the associative account, the CCAE is a manifestation of an association between the induction pattern and the induction color. The pairing of a pattern with color during induction results in the pattern evoking the adaptive response of the visual system to the induction color (i.e., the complementary color). For greenhorizontal and magenta-vertical induction, for example, one association is established between horizontal bars and green, resulting in a pink aftereffect on an achromatic horizontal grid; another association is established between vertical bars and magenta, resulting in a green aftereffect on an achromatic vertical grid. The ineffectiveness of isoluminant stimuli is attributed to selective associability between stimuli, a phenomenon that is well documented in the animal conditioning literature. For example, gastrointestinal illness is associated readily with flavor stimuli, but not with exteroceptive stimuli, in illnessinduced aversion learning studies (see Domjan, 1983).

The selective associability account of the ineffectiveness of isoluminant stimuli has been criticized for its ad hoc nature (e.g., Bedford, 1995; Broerse et al., 1994). According to the critics, selective associability provides no guidelines for how to choose which stimulus pairs will be effective and which will not. The selective associability account of isoluminant stimuli is no more ad hoc than the selective associability account of illnessinduced aversion learning. The suggestion that constraints on illness-induced aversion learning result from the innate organization of connections between the gustatory and visceral systems (e.g., Garcia, Hankins, \& Rusiniak, 1974) has proven to be useful in understanding effective and ineffective stimulus pairings in animal learning. The suggestion by Siegel and Allan (1992) that constraints on CCAE induction are imposed by the innate organization of connections between luminance- and color-perception systems (Livingstone \& Hubel, 1987) might also lead to a better understanding of effective and ineffective stimulus pairings in CCAE induction.

CCAEs are not the only perceptual phenomena affected by isoluminant stimuli. There are reports, for example, that the motion aftereffect is weaker when generated with isoluminant gratings (Cavanagh \& Favreau, 1985; Derrington \& Badcock, 1985), that moving isoluminant gratings appear to move more slowly than nonisoluminant gratings (Cavanagh, Tyler, \& Favreau, 1984), that isoluminant Mach bands are difficult to generate (Pease, 1978), that random dot stereograms using isoluminant red and green dots are less effective for stereopsis (Lu \& Fender, 1972; Simmons \& Kingdom, 1994), and that isoluminant stimuli fade relatively quickly (Kelly, 1981). Explanations of the failure of isoluminant stimuli to elicit CCAEs will need to be cognizant of this broader literature.

\section{REFERENCES}

Allan, L. G., \& Siegel, S. (1986). McCollough effects as conditioned responses: Reply to Skowbo. Psychological Bulletin, 100, 388-393.

allan, L. G., Siegel, S., Toppan, P., \& Lockhead, G. R. (1991). Assessment of the McCollough effect by a shift in psychometric function. Bulletin of the Psychonomic Society, 29, 21-24.

Allan, L. G., \& Tirimacco, N. (1987). An orientation-contingent achromatic aftereffect. Bulletin of the Psychonomic Society, 25, 54-55.

BARLOW, H. B. (1990). A theory about the functional role and synaptic mechanism of visual after-effects. In C. Blakemore (Ed.), Vision: Coding and efficiency (pp. 363-375). Cambridge: Cambridge University Press.

Barlow, H. B., \& Foldiak, P. (1989). Adaptation and decorrelation in the cortex. In R. Durbin, C. Miall, \& G. Mitchison (Eds.), The computing neuron (pp. 54-72). New York: Addison-Welsey.

BEDFORD, F. L. (1995). Constraints on perceptual learning: Objects and dimensions. Cognition, 54, 253-297.

Brand, J. L., Holding, D. H., \& Jones, P. D. (1987). Conditioning and blocking of the McCollough effect. Perception \& Psychophysics, 41, 313-317. 
Broerse, J., \& O'SheA, R. P. (1995). Local and global factors in spatially-contingent colored aftereffects. Vision Research, 35, 207 226.

Broerse, J., Shaw, C., Dodwell, P., \& Muir, D. (1994). Colored af tereffects contingent upon global transformations? Spatial Vision, $\mathbf{8}$, 95-117.

Cavanagh, P., \& Favread, O. E. (1985). Color and luminance share a common motion pathway. Vision Research, 25, 1595-1601.

Cavanagh, P., Tyler, C. W., \& Favreau, O. E. (1984). Perceived velocity of moving chromatic gratings. Journal of the Optical Society of America A, 1, 893-899.

DeRrington, A. M., \& BADCoCk, D. R. (1985). The low level motion system has both chromatic and luminance inputs. Vision Research, 25, 1879-1884

DoDWelt, P. C. (1992). Perspectives and transformations. Canadian Journal of Psychology, 46, 510-538.

DodWell, P. C., \& Humphrey, G. K. (1990). A functional theory of the McCollough effect. Psychological Review, 97, 78-89.

DODWELl, P. C., \& HuMPHREY, G. K. (1993). What is important about McCollough effects? A reply to Allan and Siegel. Psychological Review, 100, 347-350.

DOMJAN, M. (1983). Biological constraints on instrumental and classical conditioning: Implications for general process theory. In G. H. Bower (Ed.), The psychology of learning and motivation (Vol. 17, pp. 215-227). New York: Academic Press.

Eissenberg, T., Allan, L. G., Siegel, S., \& Petrov, N. (1995). An associative interpretation of the indirect McCollough effect. Quarterly Journal of Experimental Psychology, 48B, 262-286.

ELLIS, S. R, (1977). Orientation selectivity of the McCollough effect: Analysis by equivalent contrast transformation. Perception \& Psychophysics, 22, 539-544.

Garcia, J., Hankins, W. G., \& Rusiniak, K. W. (1974). Behavioral regulation of the milieu interne in man and rat. Science, 185, 824-831.

Kaiser, P. K., Herzberg, P. A., \& Boyton, R. M. (1971). Chromatic border distinctiveness and its relation to saturation. Vision Research, 11, 953-968.

KaMIN, L. J. (1969). Predictability, surprise, attention, and conditioning. In B. A. Campbell \& R. M. Church (Eds.), Punishment and aversive behavior (pp. 279-296). New York: Appleton-Century-Crofts.

KELLY, D. H. (1981). Disappearance of chromatic gratings. Science, 214, 1257-1258.

KEPPEL, G. (1991). Design and analysis: A researcher's handbook. Englewood Cliffs, NJ: Prentice-Hall.

Livingstone, M. S., \& Hubel, D. H. (1987). Psychophysical evidence for separate channels for the perception of form, color, movement, and depth. Journal of Neuroscience, 7, 3416-3468.

LU, C., \& FENDER, D. H. (1972). The interaction of color and luminance in stereoscopic vision. Investigative Ophthalmology \& Visual Science, 11, 482-490.

MCCOLlOUgh, C. (1965). Color adaptation of edge detectors in the human visual system. Science, 149, 1115-1116.

Mikaelian, H. H. (1980). Effective luminance contrast as a parameter in contingent aftereffects. Perception \& Psychophysics, 27, 531-536.

Mikaelian, H. H., Linton, M. J., \& Phillips, M. (1990). Orientationspecific luminance aftereffects. Perception \& Psychophysics, 47, 575-582.

Over, R., Broerse, J., Crassini, B., \& Lovegrove, W. (1974). Orientation-specific aftereffects and illusions in the perception of brightness. Perception \& Psychophysics, 15, 53-56.

Pease, P. L. (1978). On color Mach bands. Vision Research, 18, 751-755.
SAvoY, R. L. (1987). Contingent aftereffects and isoluminance: Psychophysical evidence for separation of color, orientation, and motion. Computer Vision. Graphics, \& Image Processing, 37, 3-19.

SiEGEL, S., \& AllaN, L. G. (1985). Overshadowing and blocking of the orientation-contingent color aftereffects: Evidence for a conditioning mechanism. Learning \& Motivation, 16, 125-138.

SiEgel, S., \& AllaN, L. G. (1992). Pairings in learning and perception: Pavlovian conditioning and contingent aftereffects. In D. Medin (Ed.), The psychology of learning and motivation (Vol. 28, pp. 127160). San Diego: Academic Press.

Siegel, S., Allan, L. G., \& Eissenberg, T. (1992). The associative basis of contingent color aftereffects. Journal of Experimental Psychology: General, 121, 79-94.

Siegel, S., Allan, L. G., \& Eissenberg, T. (1994). Scanning and formcontingent color aftereffects. Journal of Experimental Psychology: General, 123, 91-94.

Simmons, D. R., \& Kingdom, F. A. A. (1994). Contrast thresholds for stereoscopic depth identification with isoluminant and isochromatic stimuli. Vision Research, 34, 2971-2982.

Stromeyer, C. F. (1978), Form-color aftereffects in human vision. In R. Held, H. Leibowitz, \& H. L. Teuber (Eds.), Handbook of sensory physiology: Vol. 8. Perception (pp. 97-142). New York: SpringerVerlag.

WESTBROOK, R. F., \& HARRISON, W. (1984). Associative blocking of the McCollough effect. Quarterly Journal of Experimental Psychology, 36A, 309-318.

WhITE, K. D. (1976). Luminance as a parameter in the establishment and testing of the McCollough effect. Vision Research, 16, 297-302.

Wolfe J. M., \& O'ConNell, K. M. (1986). Fatigue and structural change: Two consequences of visual pattern adaptation. Investigative Ophthalmology \& Visual Science, 27, 538-543.

\section{NOTES}

1. Luminance contrast $=\left(\mathrm{L}_{\operatorname{Max}}-\mathrm{L}_{\mathrm{Min}}\right) /\left(\mathrm{L}_{\mathrm{Max}}+\mathrm{L}_{\mathrm{Min}}\right)$, where $\mathrm{L}_{\mathrm{Max}}$ denotes the maximum luminance and $\mathrm{L}_{\mathrm{Min}}$ denotes the minimum luminance.

2. Space-averaged luminance $=\left(\mathrm{L}_{\mathrm{Max}}+\mathrm{L}_{\mathrm{Min}}\right) / 2$.

3. A two-way significant interaction between assessment phase (pre and post) and induction orientation indicates the induction of a reliable CCAE, whereas a nonsignificant interaction indicates that a CCAE was not induced. We followed the significant three-way interaction with groups with planned comparisons to explore which groups would show the two-way interaction--that is, the CCAE. Our use of planned comparisons in this experiment (and in other experiments reported in this manuscript) is consistent with the views expressed by Keppel (1991).

4. This outcome appears to be the opposite of that found by White (1976) for the two subjects in his experiment. White reported that highcontrast induction resulted in a larger orientation-CCAE on a low-contrast assessment grid than on a high-contrast assessment grid. It should be noted that luminance contrast was manipulated differently in the two studies. In Experiment 1, contrast was manipulated by varying the achromatic bars - black in the high-contrast grids and gray in the lowcontrast grids. The luminance of the colored bars was the same for highand low-contrast grids. In White, the achromatic bars were always black, and contrast was manipulated by varying the luminance of the entire grid.

(Manuscript received August 26, 1996; revision accepted for publication December 10, 1996.) 